\title{
Clinical Presentations, Surgical Management and Outcome of Sinonasal Inverted Papilloma
}

\author{
Abdulrahman H Alnaji and Tariq Tatwani* \\ Department of Otorhinolaryngology, Prince Sultan Military Medical City, Saudi Arabia
}

*Corresponding author: Tariq Tatwani, Department of Otorhinolaryngology, Prince Sultan Military Medical City, Riyadh, Saudi Arabia.
Received Date: January 24, 2020

Published Date: February 24, 2020

\section{Introduction}

Sinonasal inverted papilloma (IP) also known as Schneiderian papilloma is one of the most intriguing pathology of nasal cavity and paranasal sinuses [1]. It is a benign epithelial neoplasm arising from the Schneiderian epithelium that lines the nose and paranasal sinuses [2]. Other names for this tumor include epithelial papilloma, Ringertz's tumour, transitional cell papilloma, villiform cancer and Ewing's papilloma [3]. It accounts for $70 \%$ of all sinonasal papillomas, remaining $30 \%$ are either exophyticpapillomas or columnar cell papillomas despite that it is not very common diseases $(0.5-4 \%$ of all nasal and sinus tumours). However, IP attracts considerable interest because it is locally aggressive, has a high propensity to recur, and is significantly associated with malignant transformation-most frequently to squamous cell carcinoma in about $10-15 \%$ cases $[4,5]$.

Nonetheless, there is growing evidence that human papilloma virus and environmental pollutants like cigarette smoke are convincingly implicated in pathogenesis of the tumour, its precise aetiology is still poorly understood [6,7]. Allergy, chronic longstanding inflammatory diseases and certain occupational factors are also reported as associated risk factors but their exact role in aetiology of IP is not delineated [8]. The most common site of origin of IP include lateral nasal wall and middle meatus followed by adjacent paranasal sinuses and other nearby anatomical structures like the orbit or base of skull [9]. Mostly the IP arises as a single, unilateral lesion and present with unilateral nasal obstruction [10]. However, it can rarely be multicentric and bilateral. Clinical presentation depends on the site of origin and laterality of the tumour [11]. Regarding the demographic distribution, IP is threefolds commoner in men as compared to women and peak incidence has been claimed in the $5^{\text {th }}$ to $7^{\text {th }}$ decade though the tumour has also been reported in children, adolescents and elderly [12].
Because of the tendency to recur, the ability to erode adjoining structures and the association with malignancy, in past decades most surgeons recommend medial maxillectomy via lateral rhinotomy for the treatment of IP, especially those for advance cases $[13,14]$. However, the lateral rhinotomy approach leaves permanent facial scars, which is one of the reasons why many surgeons consider it to be too invasive for the treatment of benign neoplasm. Besides the lateral rhinotomy approach, the mid facial degloving approach is a relatively uncomplicated alternative option for managing IP even when it has presented at an advance stage $[15,16]$. Furthermore, in the early 1990s, the endoscopic surgical approach was introduced for the treatment of inverted papilloma which shown comparable or even superior outcome than the conventional external approaches [17-19].

Today, it is established that IP need complete resection which may be done by either open traditional approaches or modern endoscopic resection techniques [20]. There are many reports supporting the feasibility of endoscopic resection with long-term follow-up [11,21,22]. Whether traditional approaches provide any advantage over modern endoscopic techniques is a subject of controversy and beyond the scope of this manuscript. The current study was performed to find the outcome of surgical management of inverted papillomas of the nose and paranasal sinuses in local Saudi patients.

\section{Methods}

It was a retrospective study conducted in the department of Ear Nose Throat (ENT) and Head and Neck Surgery (HNS), Prince Sultan Military Hospital/Medical City, Riyadh, Kingdom of Saudi Arabia. The patients who were histopathologically diagnosed to have an inverted type of sinonasal papilloma were retrospectively 
included in the study. All patients from any age group and gender were included in the study after obtaining informed consent, between January 1990 and March 2014. A total of 18 patients fulfilled the inclusion criteria. The clinical presentation (symptoms, signs), site, side of the lesion, duration of problem, assessment about destruction of adjacent structures, type of surgical approach performed, recurrence, association with smoking and cancer were recorded. All data was entered and analyzed with the help of SPSS version 17. Frequencies and percentages were given for qualitative/ discrete variables like gender, side and recurrence. Means were calculated for continuous/quantitative variables like age of patients and duration of symptoms. No statistical test of significance was applied as the nature of study was purely descriptive.

\section{Results}

The mean age of the patients enrolled in the study was 48.3 years. 15 patients $(83.3 \%)$ were male while 3 (16.7\%) were female (Figure 1). Male to female ratio was 5:1. Presenting males had a mean age of 46.5 years and that of females was 57.3 years. Maximum cases were reported form the age group between 21-40 years (Figure 2). The mean duration of symptoms was 2 years and 9 months ranging from 6 months to 10 years. Most common chief complaint with which the patients presented was nasal obstruction which involved 14 cases (77.8\%), followed by rhinorrhea 8 (44.4\%), postnasal drip $6(33.3 \%)$, headache $5(27.8 \%)$, epistaxis $2(11.1 \%)$ and Hyposmia 2 (11.1\%) (Figure 3).

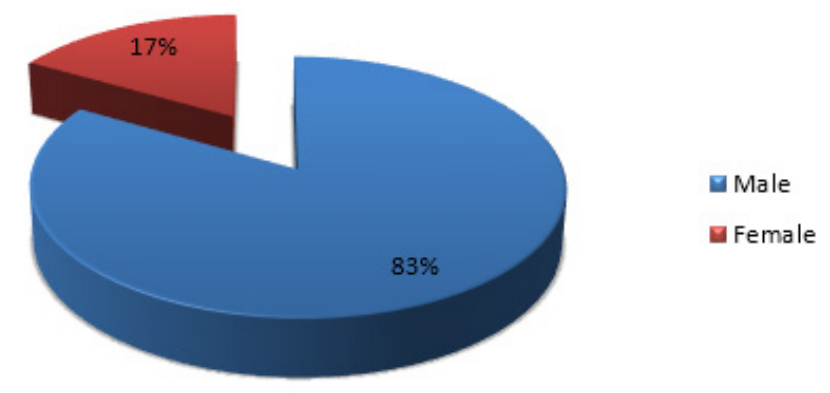

Figure 1:Gender distribution of the patients with sinonasal inverted papillomas.

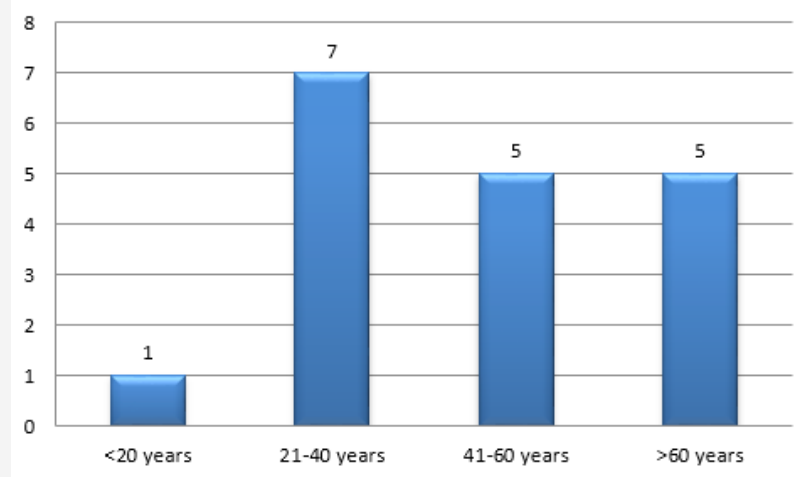

Figure 2: Age distribution of the patients with sinonasal inverted papilloms.

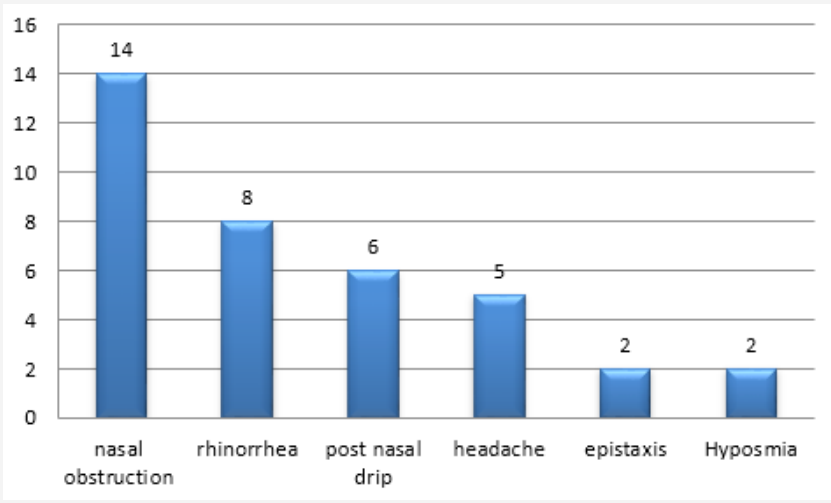

Figure 3:Presenting symptoms of sinonasal inverted papillomas. 
7 cases $(38.9 \%)$ were reported to be smokers. Sinonasal inverted papillomas involved left side in 11 cases (61.1\%) and the right side in 7 cases $(38.9 \%)$. The maxillary sinus was involved in 15 cases (83.3\%), ethmoid sinus 5 (27.8\%), sphenoid sinus 3 (16.7\%), frontal sinus $2(11.1 \%)$ and nasal septum 1 case $(5.5 \%)$ (Figure 4). Orbital extension was seen in 1 case (5.5\%) while no intracranial extension was observed. Bone erosion was observed on CT scan in 7 cases (38.9\%) while Malignancy was only observed in 1 case $(5.5 \%)$. Most commonly performed surgical procedure was endoscopic medial maxillectomy done on 6 cases (33.3\%). Other surgical procedures undertaken were lateral rhinotomy, medial maxillectomy using external approach, front ethmoidectomy, functional endoscopic sinus surgery (FESS), endoscopic excision of inverted papilloma sphenoid sinus, papilloma excision, trans-nasal resection of inverted papilloma, Caldwell-luc resection of papilloma and frontal sinusotomy with combined approach. The follow-up period ranged from 4 months to 18 years, with a mean of 6.2 years. Recurrence was observed in 3 cases (16.7\%).

Figure 4: Anatomical location/site of origin of sinonasal inverted papillomas.

\section{Discussion}

The clinical appearance of IP has been well studied. It has been reported in all age groups but is known to have a peak incidence in $5^{\text {th }}$ to $7^{\text {th }}$ decades [22-24]. Age range in our study was from 21 to 490 years (mean 48.3 years) with maximum number in the 3thand 4th decades, which is consistent with the study of Tomenzoli et al and Throp MA et al [3,7]. Our results showed Male to female ratio of $5: 1$ which is in accordance with most recorded series [23, 25].

Although the aetiology of IP is still unknown, recent studies using in situ hybridization and polymerase chain reaction have detected human papilloma virus in up to $86 \%$ of IP. In particular, viral subtypes $6,11,16$, and 18 were most frequently found $[22,26]$. The other proposed etiology for the genesis of inverted papilloma would be smoking, allergy, chronic inflammation and occupational exposure. Recently, a number of studies have been done to make genetic predilection for the origin of inverted papilloma. Keles et al [27] revealed reduced level of p27 expression correlated with increased cell proliferation in sinonasal tumours. However, variable p21 and p53 expressions were detected in both benign and $\backslash$ malignant tumours of sinonasal epithelium [28].

The clinical presentation of the IP is variable depending upon the extent of the involvement of the surrounding structures and the presence of other secondary pathology. However, the unilateral nasal obstruction is the commonest presenting symptom reported in most of the series $(9,23)$ Most common chief complaint with which the patients presented in our study was nasal obstruction which involved 14 cases (77.8) .Bilateral nasal obstruction may be due to the disease itself causing the pressure and deviation of the nasal septum towards the opposite side. In addition to that, it is due to compensatory hypertrophy of inferior turbinate of healthy side. The other presenting symptoms were rhinorrhea 8 (44.4\%), postnasal drip $6(33.3 \%)$, headache $5(27.8 \%)$, epistaxis $2(11.1 \%)$ and Hyposmia 2 (11.1\%). These results are in accordance with the findings in the literature7,9,10,15. The duration of symptoms in our series was from 6 months to 10 years with mean duration of 2 years.

This maybe due to theilliteracy, unawareness of health and health services and the poor economic condition. It is a common practice among the general population to choose the cheaper and readily available indigenous methods for treatment, before reporting to the higher center. Thorp et al [23] have reported the mean duration of symptoms of 7.2 months in their series3. Vrabec [29] reported the duration of symptoms from 2 weeks to 45 years 16 . In our study Sinonasal inverted papillomas involved left side in $61.1 \%$ and the right side in $38.9 \%$ cases. The maxillary sinus was involved in 15 cases (83.3\%), ethmoid sinus 5 (27.8\%), sphenoid sinus 3 (16.7\%), frontal sinus $2(11.1 \%)$ and nasal septum 1 case (5.5\%). Orbital extension was seen in 1 case (5.5\%) while no intracranial extension was observed. Bone erosion was observed on CT scan in 7 cases (38.9\%) while Malignancy was only observed in 1 case $(5.5 \%)$. In no cases the contralateral nasal cavity was involved. Our study is in accordance with the several other studies in terms of sinus involvement $[11,30,31]$. However, ethmoid sinus was found to be 
the commonest sinus involved followed by sphenoid and lastly the frontal sinus $[32,33]$. The higher occurrence of sinus engrossment in our series is because of the late presentation. Therefore, most of the cases presented in advanced stage of the disease.

The basic treatment of the tumour is regional resection of the mass leaving free healthy margins. This aim can be achieved more effectively with more aggressive surgery through external approach. Lateral rhinotomy and medial maxillectomy used to be the recommended surgical procedure in majority of the cases of inverted papilloma. However, more submissive endoscopic surgery is getting momentum now-a-days with controversial results. In spite of that, most authors agreed on the more subdued endoscopic surgery for very limited disease and aggressive external approach for extensive disease. Because we got cases in advanced stage, most commonly performed surgical procedure was endoscopic medial maxillectomy done on 6 cases (33.3\%). Other surgical procedures undertaken were lateral rhinotomy, medial maxillectomy using external approach, fronto-ethmoidectomy, functional endoscopic sinus surgery (FESS), endoscopic excision of inverted papilloma sphenoid sinus, papilloma excision, trans-nasal resection of inverted papilloma, Caldwell-luc resection of papilloma and frontal sinusotomy with combined approach. Our treatment policies are well supported by several other studies [30, 33-35]. In our study follow up period ranged from 4 to 18 months and our study showed recurrence in 3 cases which is much less than other studies.

\section{Conclusion}

The present study specified that the inverted papilloma is a benign but a destructive tumour of sinonasal tract. Thus, the time of presentation and time of intervention are the two key factors that affect the outcome of the treatment. The patient of IP presented late in Saudi Arabia. Majority of the patients are at hand with the sinus involvement. More belligerent surgery is the only option left for the management of this disease; however, detection of disease in early stage may provide a chance to do conservative endoscopic surgery. Larger series and extended period of prospective study and follow up is vital to determine the histological classification, to determine relation with malignant transformation, to show relation with ethnicity, to equate efficacy of diverse surgical modalities and to determine the responsible etiological factors.

\section{Acknowledgement}

None.

\section{Conflict of Interest}

The authors declare no conflict of interests.

\section{References}

1. Yasumatsu R, Nakashima T, Komune S (2013) Sinonasal inverted papilloma: a current review. Fukuoka Igaku Zasshi 104(6): 199-204.
2. Karkos PD, Fyrmpas G, Carrie SC, Swift AC (2006) Endoscopic versus open surgical interventions for inverted nasal papilloma: a systematic review. Clin Otolaryngol 31(6): 499-503.

3. Bielamowicz S, Calcaterra TC, Watson D (1993) Inverting papilloma of the head and neck: the UCLA update. Otolaryngol Head and Neck surg 109(1): 71-76.

4. Thapa N, Pradhan B (2012) Sinonasal Inverted Papilloma. Journal of Institute of Medicine 34(2): 10-13.

5. Busquets JM, Hwang PH (2006) Endoscopic resection of sinonasal inverted papilloma: a meta-analysis. Otolaryngol Head and Neck 134(3): 476-482.

6. Govindaraj S, Wang H (2014) Does human papilloma virus play a role in sinonasal inverted papilloma? Curr Opin Otolaryngol Head Neck Surg 22(1): 47-51.

7. Hong SL, Kim BH, Lee JH, Cho KS, Roh HJ (2013) Smoking and malignancy in sinonasal inverted papilloma. Laryngoscope 123(5): 1087-1091.

8. Sauter A, Matharu R, Hormann K, Naim R (2007) Current advances in the basic research and clinical management of sinonasal inverted papilloma (Review). Oncol Rep 17(3): 495-504.

9. Wolfe SG, Schlosser RJ, Bolger WE, Lanza DC, Kennedy DW (2004) Endoscopic and endoscope-assisted resections of inverted sinonasal papillomas. Otolaryngol Head and Neck Surg 131(3): 174-179.

10. Bhalla RK, Wright ED (2009) Predicting the site of attachment of sinonasal inverted papilloma. Rhinology 47(4): 345-348.

11. Pasquini E, Sciarretta V, Farneti G, Modugno GC, Ceroni AR (2004) Inverted papilloma: report of 89 cases. Am J Otolaryngol 25(3): 178-185.

12. Roland DE (2009) Inverted papilloma of the nose and paranasal sinuses in childhood and adolescence. Laryngoscope 95(1): 17-23.

13. Nadeau SH, Serrano E, Vairel B, Percodani J, Vergez S (2010) Surgical management of maxillary sinonasal inverted papilloma. Rev Laryngol Otol Rhinol (Bord) 131(4-5): 269-274.

14. Pagella F, Pusateri A, Giourgos G, Tinelli C, Matti E (2014) Evolution in the treatment of sinonasal inverted papilloma: pedicle-oriented endoscopic surgery. Am J Rhinol Allergy 28(1): 75-81.

15. Cansz H, Tahamiler R, Yener M, Acoglu E, Guvenc MG, et al (2008) Modified midfacial degloving approach for sinonasal tumors. J Craniofac Surg 19(6): 1518-1522.

16. Kim HJ, Kim CH, Kang JW, Shin WC, Kim YS, et al. (2011) A modified midfacial degloving approach for the treatment of unilateral paranasal sinus tumours. J Craniomaxillofac Surg 39(4): 284-288.

17. Carta F, Verillaud B, Herman P (2011) Role of endoscopic approach in the management of inverted papilloma. Curr Opin Otolaryngol Head Neck Surg 19(1):21-24.

18. Pagella F, Giourgos G, Matti E, Canevari FR, Carena P (2011) Endoscopic treatment of maxillary inverted papilloma. Rhinology 49(3): 369-374.

19. Habib AR, Hathorn I, Sunkaraneni VS, Srubiski A, Javer AR (2013) Blood transfusion requirements for endoscopic sinonasal inverted papilloma resections. J Otolaryngol Head Neck Surg 42: 1-44.

20. Lane AP, Bolger WE (2006) Endoscopic management of inverted papilloma. Curr Opin Otolaryngol Head Neck Surg 14(1): 14-18.

21. Kraft M, Simmen D, Kaufmann T, Holzmann D (2003) Long-term results of endonasal sinus surgery in sinonasal papillomas. Laryngoscope 113(9): 1541-1547.

22. Tomenzoli D, Castelnuovo P, Pagella F, Berlucchi M, Pianta L, et al (2004) Different endoscopic surgical strategies in the management of inverted papilloma of the sinonasal tract: experience with 47 patients. Laryngoscope 114(2): 193-200. 
23. Thorp M, Oyarzabal Amigo M, Du Plessis J, Sellars S (2001) Inverted papilloma: a review of 53 cases. Laryngoscope 111(8): 1401-1405.

24. Yoon JH, Kim CH, Choi EC (2002) Treatment outcomes of primary and recurrent inverted papilloma: an analysis of 96 cases. J Laryngol otol 116(9): 699-702.

25. Kaufman MR, Brandwein MS, Lawson W (2002) Sinonasal papillomas: clinicopathologic review of 40 patients with inverted and oncocytic schneiderian papillomas. Laryngoscope 112(8 Pt 1):1372-1377.

26. Marioni G, Altavilla G, Busatto G, Blandamura S, De Filippis C, et al (2003) Detection of human papillomavirus in temporal bone inverted papilloma by polymerase chain reaction. Acta otolaryngol 123(3): 367 371.

27. Keles N, Erdamar B, Kaur A, Deger K (2003) p21, p53, and p27 Kip1 alterations in benign and malignant tumors of sinonasal epithelium. Otolaryngol Head Neck Surg 129(1): 77-84.

28. Wormald PJ, Ooi E, Van Hasselt CA, Nair S (2003) Endoscopic removal of sinonasal inverted papilloma including endoscopic medial maxillectomy. Laryngoscope 113(5): 867-873.

29. Vrabec DP (1975) The inverted Schneiderian papilloma: a clinical and pathological study. Laryngoscope 85(1): 186-220.
30. Lawson W, Patel ZM (2009) The evolution of management for inverted papilloma: an analysis of 200 cases. Otolaryngol Head Neck Surg 140(3): 330-335.

31. Phillips PP, Gustafson RO, Facer GW (1990) The clinical behavior of inverting papilloma of the nose and paranasal sinuses: report of 112 cases and review of the literature. Laryngoscope 100(5): 463-469.

32. Han JK, Smith TL, Loehrl T, Toohill RJ, Smith MM (2001) An evolution in the management of sinonasal inverting papilloma. Laryngoscope 111(8): 1395-1400.

33. Klimek T, Atai E, Schubert M, Glanz H (2000) Inverted papilloma of the nasal cavity and paranasal sinuses: clinical data, surgical strategy and recurrence rates. Acta oto-laryngol 120(2): 267-272.

34. Barbosa JL, Pinheiro SD, Freitas MR, Nunes AA, Leite EB (2012) Sinonasal inverted papilloma involving the middle ear and the mastoid. Braz J Otorhinolaryngol 78(6): 1-122

35. Bhandary S, Singh RK, Sinha AK, Badhu BP, Karki P (2006) Sinonasal inverted papilloma in eastern part of Nepal. Kathmandu Univ Med J (KUMJ) 4(4): 431-435. 